DOI: https://doi.org/10.34137/jilses.592946

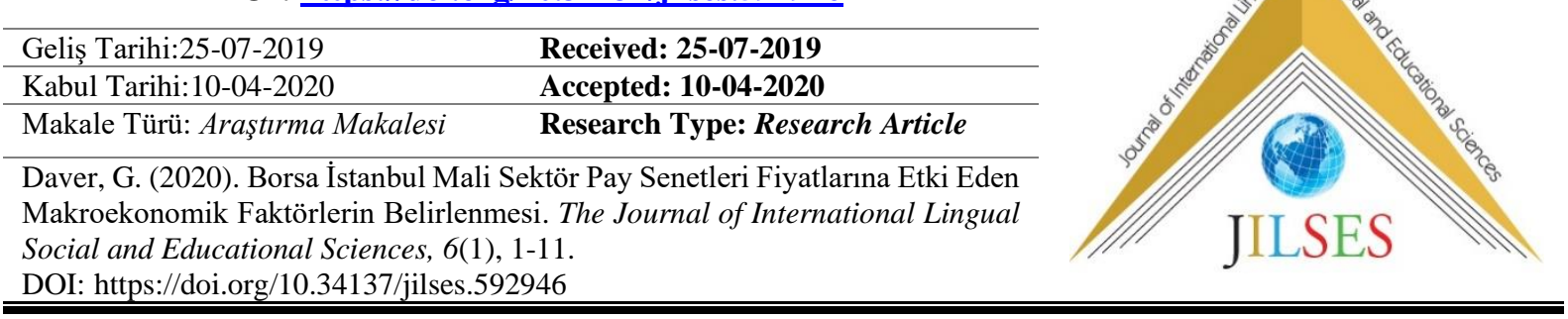

\title{
Borsa İstanbul Mali Sektör Pay Senetleri Fiyatlarına Etki Eden Makroekonomik Faktörlerin Belirlenmesi*
}

\author{
Gizay DAVER ${ }^{1}$ \\ $\ddot{O} z$
}

Finansal bă̆lantılılık kapsamında tesis edilecek görece proaktif risk yönetim sistemlerinin kurulmasında, kullanılması uygun olabilecek faktörlerin tespit edilmesinin amaçlandığ çalışmada 2011:01 - 2018:12 dönemi için TCMB EVDS'den seçilen ayllı verilerle Borsa Ístanbul mali sektör endeksi ve Borsa İstanbul ulusal endeksi getirilerinin çoklu doğrusal regresyon modeliyle açıklanabilirliği araştırılmıștır. Borsa İstanbul ulusal endeksi için kurulan modelin istatistiki olarak anlamlı olmadi $\breve{g}$, Borsa İstanbul mali sektör endeksi için kurulan modelin ise istatistiki olarak anlamlı olmasına rağmen modelin açılama gücünün düşük olduğu ve M2 haricinde diğer tüm değiş̧kenlerin istatistiki olarak anlamsız görüldüğ̈̈ tespit edilmiştir. Değiş̧en varyans probleminin bulunma ihtimaline yönelik bulguların tespit edilmesiyle risk gözetim mekanizması tesis edilmeye çalışırken uygun olabilecek faktörlerin belirlenmesi için farklı modellerle çalışmanın daha uygun olacağı sonucuna ulaşılmıştır.

Anahtar Kelimeler: Finansal bağlantılllık, risk yönetim sistemleri, pay senedi getirileri

\section{Determination of Macroeconomic Factors Influencing Borsa Istanbul Financial Sector Stock Prices}

\begin{abstract}
In the study, which aims to determine the factors that may be suitable for the establishment of relatively proactive risk management systems within the scope of financial connectivity, the explanoratory power of the Borsa Istanbul financial sector index returns and the Borsa Istanbul national index returns was investigated. Multiple linear regression models were established from the selected CBRT EDDS monthly data for the period 2011: 01 - 2018: 12. It was found that the model established for Borsa Istanbul national index was not statistically significant, although the model established for Borsa Istanbul financial sector index was statistically significant, the explanatory power of the model was low and all other variables except M2 were considered statistically insignificant. It was concluded that it would be more appropriate to work with different models in order to determine the factors that may be appropriate when trying to establish a risk surveillance mechanism by identifying the findings regarding the possibility of changing variance problem.
\end{abstract}

Keywords: Financial interconnectedness, risk management systems, stock returns

\footnotetext{
* Bu makale Uluslararası ASOS Kongresi'nde (Alanya, 2019) sunulan sözlü bildirinin tartışma ve değerlendirmeler çerçevesinde geliştirilmiş ve değiştirilmiş versiyonudur.
}

${ }^{1}$ Dr. Öğr. Üyesi, Zonguldak Bülent Ecevit Üniversitesi, gizaydaver@gmail.com, https://orcid.org/0000-0001-5427-0741 


\section{Giriş}

Finansal ekosistemde yer alan aktörler arasındaki ilişkiler ağı küreselleşmenin getirdiği bağlantılar sayesinde çok geniş kitleleri etkilemektedir. Etkilerin sınırları, finansal sistemdeki unsurların finansal bağlarının kuvvetine göre şekillenmektedir. Finansal bağlantılılık kapsamında incelenebilecek pek çok değişken bulunmaktadır. Bu değişkenler tek bir ülke örneklemi için kurulabileceği gibi çoklu ülke örneklemleri için de kurulabilmektedir. Türkiye özelinde 1991 - 2006 döneminde iki farklı regresyon modeliyle dar tanımlı para arzı, enflasyon ve uzun vadeli faiz oranlarının bağımsız değişkenler olarak tanımlanarak sırasıyla mali endekse ve ulusal 100 endeksine etkilerinin incelendiği çalışmada, hem mali endeksle hem de ulusal 100 endeksiyle enflasyon ve para arzı arasında doğru yönlü ilişkinin varlığı, uzun vadeli faiz oranlarıyla ise ters yönlü bir ilişkinin varlığı tespit edilmiştir (Omağ, 2009). Aralarında Türkiye'nin de bulunduğu Arjantin, Brezilya, Endonezya, Macaristan, Malezya, Meksika, Polonya, Rusya, Şili ve Ürdün'den oluşan gelişmekte olan 11 ülke için 1996 - 2006 dönemindeki hisse senedi getirilerine M1 para arzı, faiz oranları, gayrisafi yurtiçi hasıla, döviz kuru, petrol fiyatları, tüketici enflasyonu ve Standard and Poors 500(S\&P500) endeksinin getirisi olarak seçilen 7 adet açıklayıcı değişkenin etkisinin incelendiği çalışmada, hisse senedi getirileriyle faiz oranı, reel ekonomik faaliyetin göstergesi gayrisafi yurtiçi hasıla, para arzı ve petrol fiyatı değişimi arasında istatistiki olarak anlamlı bir sonuç elde edilememişken, hisse senedi getirileriyle S\&P500 ve enflasyon oranı arasında pozitif bir ilişki olduğu, döviz kuruyla ise negatif bir ilişki olduğu belirtilmiştir(Sayılgan \& Süslü, 2011). Almanya, Fransa, İngiltere, Kanada, Japonya, Amerika ve İtalya'dan seçilen DAX, CAC 40, FTSE, S\&P TSX Composite, NIKKEI 225, S\&P500, DOW JONES, NASDAQ ve MIBTEL endeksleri için datastream veri tabanından elde edilen 04.01.1988 - 31.12.2004 dönemini kapsayan borsa günlük kapanış verileriyle, G7 ülkelerinin borsalarının Türkiye borsası(IMKB 100) üzerindeki etkileri incelenmiş ve özellikle küreselleşmeye bağlı olarak 2002 yılından sonra G7 ülkelerinin borsalarının İMKB 100 üzerindeki etkisinin arttığı belirtilmiştir(Ceylan, 2005). Gerek tek bir ülke içerisindeki değişkenlerin diğer değişkenler üzerine etkisinin incelenmesinde, gerekse bir ülkedeki değişken veya değişkenlerin diğer bir ülkeye yapacağı etkilerin incelenmesinde finansal bağlantılılık kavramı önem arz etmektedir. Bu çalışmada, Türk mali sistemi finansal bağlantılılık çerçevesinde ele alınmıştır. Finansal bağlantılılık kapsamında, büyük varlık hacmine sahip bankaların ayrıca aynı anda birçok sektöre finansal altyapı hizmeti sunan bankalar ve banka dışı finansal kuruluşların son olarak da sistemik öneme sahip finansal kuruluşların biriken risklerinin sürekli biçimde gözetilmesi ihtiyacı, risk gözetim mekanizmaları tesisini gerektirmektedir. Doğrudan veya dolaylı bağlantılık kapsamında ele alınabilecek risk gözetim mekanizmaları, izlenen bağlantılılık yöntemine uygun farklı faktörlerin izlenmesini gerektirmektedir. Bu çalışmada makroekonomik faktörlerin hisse senetleri fiyatları üzerindeki etkisinden hareket edilmektedir.

\section{Literatür}

1926 - 2015 döneminde Amerika için hisse senedi piyasaları getirilerini likidite azlığı ölçütleri volatilitesiyle ve model kalanları ile tahmin edebilme durumu incelenmiştir. Kullanılan likidite azlığı ölçütleri, pay senedi getirileri ve ilgili finansal değişkenler, makroekonomik aktivite ölçütleri değişkenler olarak üç başlikta toparlanmıştır. Likidite azlığı ölçütleriyle pay senetleri fiyatlarını ve reel ekonomik aktiviteyi tahmin mümkündür sonuçlarına ulaşılmıştır(Chen, Eaton, \& Paye, 2018). 1999 - 2017 döneminde Belçika, Fransa, Almanya, Hollanda ve Portekiz için hisse senedi fiyatları ile temel makroekonomik değişkenler arası ilişki incelenmiştir. Kullanılan değişkenler enflasyon, endüstriyel üretim, faiz oranları, para arzı olup, ülkeden ülkeye farklı etki varlığı ve aynı ülkede dönemler arasında etkilerin değişebildiği sonuçlarına ulaşılmıştır(Camilleri, Scicluna, \& Bai, 2019). 2001 - 2006 döneminde The S\&P Emerging Market Datebase'den Arjantin, Brezilya, Endonezya, Fas, Filipinler, Güney Afrika, Güney Kore, Hindistan, Kolombiya, Macaristan, Malezya, Meksika, Pakistan, Polonya, Rusya, Şili, Tayland, Tayvan, Türkiye, Venezüella olarak seçilen 20 ülke için ABD dolarının değerindeki değişimin ülkelerin hisse senedi pazar endeksleri üzerindeki etkisi incelenmiştir. Kullanılan değişkenler ABD Doları ve ülke endeksleri olup, bağımsız değişken seçiminin istatistiki anlamı değiştirmekte olduğu belirlenmiştir. Kurulan modellerde bağımsız değişken olarak sadece döviz kurlu modelde istatistiki olarak anlamlı ilişki tespit edilmiştir. Bir, iki ve üç aylık gecikmelerle yapılan çalışma sonucunda ABD Doları'nın 1 aylık gecikmeli etkisinin Türkiye için negatif yönlü olduğu sonucuna ulaşılmıştır(Karacaer \& Topuz, 2009). 2006 - 2018 döneminde beş gelişmiş sermaye piyasası (Amerika, Kanada, Fransa, Almanya, İngiltere) için piyasalar arası bağlantılılık ve şokların ülkeler arası iletimi incelenmiştir. Kullanılan değişkenler, endeksler(S\&P 500, TSX 60, CAC 40, DAX 30 ve FTSE 100) olup, Avrupa'da kendi içersinde finansal bulaşma varlığ 1 tespit edilmiştir. Özellikle kriz dönemlerinde Amerika ve Kanada'ya bulaşma etkisinin esas olarak Avrupa ülkelerinden kaynaklanmakta olduğu sonuçlarına ulaşılmıştır(BenMim \& BenSaïda, 2019). 2006 - 2018 döneminde Meksika için Meksika pay senedi piyasası endeksi(Mexican Stock Exchange BMV IPC) üzerine makroekonomik değişkenlerin etkileri incelenmiştir. Kullanılan değişkenler Mexican Stock Exchange BMV IPC, petrol fiyatları, altın fiyatları, döviz kuru olup, bileşen etkisinin yönü ve ilişkisi vadeyle de ilişkilendirilmelidir bulgularınaulaşılmıştır. Meksika'ya, uluslararası altın fiyatlarının etkisi pozitif, petrol fiyatlarının etkisi negatiftir. Uzun vadede petrol ve altın fiyatları pay senetleri fiyatlarından ve döviz kuru oynaklığından bağımsızdır. Uzun vadede petrol fiyatları ve döviz kuru pay senedi 
piyasasını negatif etkilemektedir. Altın fiyatlarının da pay senedi piyasası hareketlerinde etkisi vardır sonuçlarına ulaşılmıştır(Singhal, Choudhary, \& Biswal, 2019). 2014 - 2018 döneminde Amerika için S\&P 500 VIX Futures endeksi günlük işlem hacmiyle S\&P 500 VIX Futures endeksi ilişkisi incelenmiştir. Kullanılan değişkenler S\&P 500 VIX Futures Endeksi günlük işlem hacmi, S\&P 500 VIX Futures Endeksi kapanış fiyatları olup, yüksek işlem hacimleri daha yüksek getirilere ve daha fazla volatiliteye öncülük edebilmektedir. Tekrarlanan bilgiler piyasada yatırımcıların satın alma kararlarını etkilemektedir ve etkilerin gecikmeleri bir işlem gününden üç işlem gününe kadar gözlemlenebilmektedir sonuçlarına ulaşılmıştır(Kao, Chuang, \& Ku, 2019). 1986 - 1998 döneminde Türkiye için İMKB'ye etki eden faktörler incelenmiştir. Kullanılan değişkenler enflasyon, faiz oranı, sanayi üretim endeksi, döviz kuru, para arzı olup, Yalnızca faiz oranı negatif katsayıyla istatistiksel anlamlılığa sahiptir sonuçlarına ulaşılmıştır(Durukan, 1999). 1986 - 2003 döneminde Türkiye için İMKB endeksindeki oynaklık değişiminin kullanılan makroekonomik değişkenlerden kaynaklanma durumu incelenmiştir. Kullanılan değişkenler M1 para arzı, TÜFE, döviz kuru, petrol fiyatları endeksi olup, makroekonomik oynaklıkların sınanması sonucunda sadece sınai üretim ve döviz kuru oynaklıklarının hisse senedi piyasası oynaklığı ile anlamlı ilişki içersinde olduğu belirtilmiştir. Hisse senedi piyasasındaki oynaklığın \%6'sının makroekonomik oynaklıktaki değişmeyle açıklandığı ifade edilmiştir(Kırbaş Kasman, 2005). 1988 - 2015 döneminde Türkiye Cumhuriyet Merkez Bankası döviz rezervlerine etki eden makroekonomik faktörlerin belirlenmesine çalışılmıştır. Kullanılan değişkenler döviz rezervi, ekonomik büyüme, cari işlemler dengesinin GSYİH rakamına oranı, Amerikan Doları faiz oranı, Amerikan Doları Türk Lirası TCMB döviz alış kuru, Türk Lirası faiz oranı, enflasyon oranı olup, Türkiye Cumhuriyet Merkez Bankası(TCMB)'nın rezerv miktarını etkilemekte olan 3 adet bağımsız değişken tespit edilmiştir. Cari işlemler dengesi ve ABD Doları faiz oranının merkez bankası rezervlerini pozitif yönde etkilediği, TL faiz oranı ve TCMB döviz rezervleri arasındaki ilişkinin ise negatif yönlü olduğu belirtilmiştir(Yüksel \& Özsarı, 2017). 1992 - 2006 döneminde Türkiye için İMKB endeksini etkileyen makroekonomik değişkenler incelenmiştir. Kullanılan değişkenler hazine bonosu faiz oranı, TÜFE, M2 para arzı, sanayi üretim endeksi, dolar, altın fiyatları olup, kriz dönemleri ve normal dönemlerde sonuçlar farklılaşmaktadır. İMKB üzerinde normal zamanlarda tüm değişkenler etkiliyken, kriz dönemlerinde TÜFE ve M2 etkilidir.Hisse senedi fiyatları ile tüketici fiyat endeksi (TÜFE) arasında negatif yönde, para arzı (M2) arasında ise pozitif yönde anlamlı bir ilişki bulunmaktadır. Normal dönemlerde altın, tüketici fiyat endeksi ve para arzı ile endeks arasında pozitif yönlü, sanayi üretim endeksi, dolar ve hazine bonosu faiz oranları ile endeks arasında negatif yönlü ilişki bulunmuştur(Gençtürk, 2009). 1995 - 2012 döneminde 75 Ülke panel analizine tabi tutulmuştur. Türkiye Panel A'da Doğu Avrupa Ülkeleriyle sınıflanmıştır. Çalışmada konut fiyatlarındaki değişimi açıklayan makroekonomik değişkenler incelenmiştir. Kullanılan değişkenler yıllık kredi faiz oranları, yıllık kişisel harcanabilir gelir, istihdam, nüfus, gayrisafi yurtiçi hasıla olup, bu değişkenlerle konut fiyatlarında meydana gelen değişimler büyük oranda açıklanabilmektedir. Doğu Avrupa ülkelerinde, yıllık borçlanma faiz oranları ile konut fiyat endeksi arasında diğer bütün bölgelerin aksine negatif bir ilişki bulunmuştur. İstihdam ile konut fiyat endeksi arasında diğer bütün bölgelerin aksine pozitif bir ilişki bulunmuştur(Çankaya, 2013). 1996 - 2009 döneminde Türkiye için İMKB 100 ile makro ekonomik değişkenlerin ilişkisi incelenmiştir. Kullanılan değişkenler faiz oranı, para arzı, dış ticaret dengesi, sanayi üretim endeksi, altın fiyatları, döviz kuru ve tüketici fiyat endeksi olup, İMKB ile tüm değişkenler arasında anlamlı ilişkiler bulunmuştur. Hisse senedi fiyatı ile tüketici fiyat endeksi, faiz oranı, para arzı, dış ticaret dengesi ve sanayi üretim endeksi değişkenleri arasında uzun dönemli bir ilişki bulunmaktadır. Hisse senedi fiyatları ile döviz kuru değişkeni dışında tüm değişkenlerle tek yönlü nedensellik ilişkisi bulunmaktadır. Hisse senedi fiyatları ile tüketici fiyat endeksi, dış ticaret dengesi ve faiz oranı değişkenleri hisse senedi fiyatlarının nedenini oluşturmaktadır. Altın fiyatları, para arzı ve sanayi üretim endeksi değişkenleri tek yönlü olarak hisse senedi fiyatlarından etkilenmektedir. Hisse senedi fiyatları üzerine en fazla etki kendi şoklarından kaynaklanmaktadır daha sonraysa dış ticaret dengesi, sanayi üretim endeksi, tüketici fiyat endeksi, faiz oranı, para arzı, altın fiyatları, döviz kuru ve değişkenlerinin şokları etkili olmaktadır sonuçlarına ulaşılmıştır(Özer, Kaya, \& Özer, 2011). 1998 - 2010 döneminde Türkiye için yabancı portföy yatırımlarının belirleyicilerinin tespiti konusu incelenmiştir. Kullanılan değişkenler, yabancı portföy yatırımcılarının İMKB'den yapmış oldukları alış ve satış tutarları ile Türkiye ekonomisinden seçilmiş ABD dolar faizi, GSYİH, ABD Dolar kuru, Merkez Bankası döviz rezervi, ödemeler dengesi tutarı,tüketici fiyat endeksi , ticari açıklık, finansal açıklık , İMKB 100 endeksi büyüme oranı, makro ekonomik değişkenler ve International Country Risk Guide (ICRG) tarafından tespit edilmiş Türkiye'nin ekonomik riski, Türkiye'nin finansal riski , Türkiye'nin politik riski. olup, belirleyicilerinin dış ticaret dengesi, dolar faiz oranı, gayri safi yurtiçi hasıla, enflasyon, ticari açıklık, finansal açıklık, İMKB 100 endeksi, ekonomik risk ve finansal risk faktörleri olduğu sonuçlarına ulaşılmıştır(Kaya \& Öndeş, 2013). 2003 - 2017 döneminde Türkiye için hisse senedi getirilerini açıklayan faktörler incelenmiştir. Kullanılan değişkenler döviz kuru, mevduat faiz oranı, enflasyon oranı, altın fiyatları, M1 para arzı, petrol fiyatları, dış ticaret dengesi, sanayi üretim endeksi olup, reel hisse senedi getirilerinin çoğunlukla kendi gecikmeli değerlerinin etkisi altında kaldığı tespit edilmiştir. Reel hisse senedi getirilerini açıklamada altın fiyatları, dış ticaret dengesi, sanayi üretim endeksi ve faiz oranı etkili olup, enflasyon oranı, para arzı, reel petrol fiyatları değişkenlerinin reel hisse senedi getirilerindeki değişimleri açıklamada önemsizdir sonuçlarına ulaşılmıştır(Alper \& Kara, 2017). Altı içsel ve üç dışsal değişken seçilerek 2004 - 2015 döneminde Türk Bankacılık sektörünü 
etkileyen faktörler incelenmiştir. İçsel değişkenler sermaye yeterliliği ve aktif kalitesi, karlılık, piyasa riski ve bilinen sağlamlık endekslerinden farklı olarak kredi riski (faiz riski + kur riski) temel bileşenleri bir araya getirilerek oluşturulan bankacılık sağlamlık endeksi (BSI), Türkiye'nin ülke risk primi, reel efektif döviz kuru, finansal sektörün hisse senedi fiyat endeksi, bankalararası para piyasası gecelik faiz oranı, kredi-mevduat faiz fark1 olarak, dışsal değişkenler ise ABD'nin iki yıllık hazine tahvillerinin faiz oranı, dolar cinsinden brent petrolün varil fiyatı ve VIX olarak bilinen küresel risk iştahı endeksi olarak seçilmiştir. Bankacılık sektörünün bilânço yapısında meydana gelen yapısal şoklar konusunda yapılan tespitler ülke risk primi, döviz kuru ve kredi-mevduat faiz farkı değişkenlerinin etkisinin gücünün sınırlı bir düzeyde olduğu, kredi - mevduat faiz farkı değişkeninde meydana gelen yapısal şokların açıklanmasında ülke risk primi, döviz kuru ve bankacılık sağlamlık endeksi değişkenlerinin etki gücünün yüksek düzeyde olduğu yönündedir. Ülke risk primi şoklarının bankacılık sektörü bilanço yapısına olumsuz etkilerinin bir ay sürdüğünü; ancak bir aydan daha uzun bir süre içerisinde reel ekonomiye faiz kanalıyla etki ettiği sonuçlarına ulaşılmıştır(Varlık, 2017). 2005 - 2015 döneminde Türkiye için BİST ve makroekoomik değişkenlerin nedensellik ilişkisi ve makroekonomik değişkenlerdeki şokların BİST'e etkisi incelenmiştir. Kullanılan değişkenler faiz oranı, döviz kuru, ihracat miktarı, ithalat miktarı, sanayi üretim endeksi ve altın fiyatı olup, sanayi üretim endeksi, döviz kuru, altın BİST'te artışa; ihracat, ithalat ve faiz BİST'te azalış a neden olmaktadır. BİST’ten sanayi üretim endeksine, ihracat ve ithalata tek yönlü bir nedensellik ilişsisi belirlenmiştir. Ayrıca döviz kurundan BİST'e doğru tek yönlü bir nedensellik ilişkisi tespit edilmiştir(Coşkun, Kiracı, \& Muhammed, 2016). 2007 - 2017 döneminde Türkiye için makro ekonomik faktörlerin Borsa İstanbul Banka Endeksine etkisi incelenmiştir. Kullanılan değişkenler, makroekonomik faktörler, TLUSD alış ve satış ortalaması, mevduatlara uygulanan ağırlıklı ortalama faiz oranı, yurt içi üretici fiyat endeksi, 1 ons altın Londra satış fiyatı ve M2 olup, istatistiksel olarak anlamlı ve negatif yönlü ilişki tespit edilen pay senedi getirisi ile döviz kuru, faiz oranı ve para arzı olup, arasında herhangi bir ilişki tespit edilemeyen altın fiyatı ve enflasyon oranı ile pay senedi getirisidir. Para arzı ile pay senedi getirisi arasındaki anlamlı ancak negatif yönlü ilişki tespit edilmiştir(Topaloğlu \& Karakozak, 2018). 2008 yılında Türkiye için İMKB'de işlem gören leasing şirketlerinin fiyatlamasını etkileyen faktörlerin belirlenmesine çalışılmıştır. Kullanılan değişkenler İMKB endeksi, leasing şirketlerinin kapanış fiyatları ve KDV oranı değişiklikleri olup, İMKB zayıf formda etkin veya güçlü formda etkin bir piyasa olarak düşünülebilir çıkarımı yapılmıştır. KDV oranı değişiklikleri fiyatlamayı etkilememiştir, yani risk olarak algılanmamıştır sonuçlarına ulaşılmıştır(Koçyiğit \& Kılıç, 2008). 2010 - 2013 döneminde Türkiye için BİST'te Sendikasyon kredisi anlaşmaları sayesinde anormal getiri elde etme olanağı incelenmiştir. Kullanılan değişkenler BİST endeksi ve bankaların kapanış fiyatları ve sendikasyon kredisi kullanımları olup, normal üstü getiri elde etmenin mümkün olduğu ve piyasaların zayıf formda etkin olduğu sonuçlarına ulaşılmıştır(Sakarya \& Sezgin, 2015). 2005 - 2016 döneminde Türkiye için BİST 100 'e etki eden makroekonomik değişkenlerin belirlenmesi konusu incelenmiştir. Kullanılan değişkenler tüketici fiyat endeksi(bir önceki yılın aynı ayına göre yüzde değişim oran), Amerikan doları, Euro, emisyon hacmi(M2 para arzı) ve petrol fiyatı(Batı Texas brent fiyatı) olup, TÜFE göstergesinin değeri negatif, emisyon hacminin etkisi pozitif bulunmuştur. Petrol fiyatlarındaki artış Türkiye'nin petrole olan talebini daha hızlı arttırmıştır. Dolarla pozitif etkileşim, Euro ile negatif ilişki ortaya konulmuştur. Döviz ile pay fiyatları arasında negatif ilişki vardır sonuçlarına ulaşılmıştır(Uçan, Güzel, \& Acar, 2017). Literatürden de görüleceği üzere makroekonomik değişkenlerin etkileri ülkeler arasında, aynı ülkede dönemler arasında, aynı dönemde aynı ülkede kullanılan değişken seçiminde bile farklı sonuçlar ortaya çıkarabilmektedir.

\section{Çalışmanın amacı}

2011 - 2019 yılları arasındaki veriler kullanılarak finansal bağlantılılık kapsamında tesis edilecek risk yönetim sistemlerinin kurulmasında, kullanılması uygun olabilecek faktörlerin tespit edilmesi amaçlanmıştır. Gecikmeli olarak açıklanan ekonomik veriler risk yönetim sistemleri açsından reaktif yaklaşımları zorunlu kılmaktadır. Çok gecikmeye meal vermeden, görece proaktif bir sistem kurulabilmesi için, seçilen ayılık verilerle Borsa İstanbul mali sektör endeksi ve Borsa İstanbul ulusal endeksi getirilerinin açıklanabilirliği araştırılması amaçlanmıştır.

\section{Yöntem}

\section{Araştırma modeli}

Literatürden hareketle araştırma modeli olarak çoklu doğrusal regresyon modeli kullanılmasına karar verilmiştir. En geniş tanımıyla regresyon bir değişkendeki hareketleri bir veya daha fazla değişkendeki hareketle açıklama çabasıdır(Brooks, 2008). Bağımsız değişkenler x ile bağımlı değişken y ile ifade edilmiştir. Çoklu doğrusal regresyon modelinin genelleştirilmiş ifadesi (1) numaralı denklemde gösterilmiştir(Brooks, 2008, s. 89).

$$
y_{t}=\beta_{1}+\beta_{2} x_{2 t}+\ldots+\beta_{k} x_{k t}+u_{t}, t=1,2, \ldots, T
$$

Bağımlı değişken y’yi açıklayan k-1 tane bağımsız değişken olup betalar bu değişkenlerin her birinin y üzerine etkisini gösteren parametreleridir. Tanımlanan denklemdeki t gözlem numarasını, $\mathrm{u}$ ise hata terimini ifade etmektedir(Brooks, 2008, s. 89). 


\section{Verilerin toplanması}

Literatür çalışmaları ve mali sektörle etkileşimi gözetilerek Borsa İstanbul Mali Sektör Pay Senetleri Fiyatlarına ve BİST 100 endeksine eden aylık faktörlerin belirlenmesi için TCMB elektronik veri dağıtım sisteminden(EVDS) faydalanılmıştır. Aylık olarak açıklanan toplam yedi adet bağımsız değişken seçilmiştir. TCMB ağırlıklı ortalama fonlama maliyeti kısıt oluşturduğu için 2011:01 - 2018:12 arası çalışma dönemi olarak belirlenmiştir. TCMB, EVDS sisteminden indirilen, 1 Ons Altın Londra Satıș Fiyatı (ABD Doları/Ons)-Düzey, (FIYAT) BIST 100 Endeks, Kapanış Fiyatlarına Göre(Ocak 1986=1)-Düzey, (FIYAT) BİST Mali Endeks Kapanış Fiyatlarına Göre (31-12-1990=33)-Düzey, TCMB Ağırlıklı Ortalama Fonlama Maliyeti-Düzey, (USD) ABD Doları (Döviz Alış)Düzey, (USD) ABD Doları (Döviz Satış)-Düzey, M2(Bin TL)-Düzey, Tüketici Fiyat Endeksi (Genel)-Düzey, Konut Fiyat Endeksi (KFE)-Düzey, Genel Bütçe Dengesi-Düzey, MBONCU-SUE (Trend Kapsayan)-Düzey, Tarım dışı işsizlik oranı (\%)-Düzey, serileri çalışmanın verilerini oluşturmuştur.

\section{Verilerin analizi}

Veriler Eviews7 paket programı ile analize tabi tutulmuştur. Belirtilmesi gereken önemli noktalar şöyledir: Düzey değişkenlerin hepsi logaritmik getiriye çevrilmiştir. Çalışma için iki adet regresyon modeli oluşturulmuştur. Bağımlı değişkenin BİST 100 endeksi seçildiği birinci regresyon denklemi ve bağımlı değişkenin BİST Mali endeksi seçildiği ikinci regresyon denklemi. Modellerin çoklu doğrusal regresyon analizinin koşullarını sağlama durumları kontrol edilmiştir. Klasik doğrusal regresyon modeli varsayımları ve tanı testleri için (Brooks, 2008) prosedürleri takip edilmiştir. Prosedürler arasında hata terimlerinin ortalamasının sıfır olması, homoskadastisite varsayımı ve heteroskedastisite belirlenmesi, hata terimlerinin birbirleriyle korelasyon içerisinde olmaması otokorelasyonun bulunmaması, normal dağılım durumları incelenmiştir. Ayrıca multicollinearity veya çoklu doğrusal bağıntı incelemesi de gerçekleştirilmiştir.

\section{Bulgular ve Yorumlar}

Kurulan modellerde kullanılan kısaltmalara ilişkin olarak rt getiriyi, ln logaritmayı ifade etmektedir. Logaritmik getiriden sonra gelen, usd_a dolar alış kurunu, tufe tüketici fiyat endeksini, tdı tarım dışı işsizliği, m2 para arzını, kfe konut fiyat endeksini, clı sanayi üretim endeksini, aulon altın fiyatlarını, apıfon ağırlıklı ortalama fonlama maliyetini ifade etmektedir. Denklemin sol tarafında kalan bağımlı değişkenlerden XU100 BİST 100 endeksini, XMALI BİST Mali endeksini ifade etmektedir.

$$
\begin{aligned}
& \text { LNRTXU100 = C(1)*LNRTUSD_A + C(2)*LNRTTUFE + C(3)*LNRTTDI + C(4)*LNRTM2 } \\
& + \text { C(5)*LNRTKFE + C(6)*LNRTCLI + C(7)*LNRTAULON + C(8)*LNRTAPIFON + C(9) } \\
& \text { LNRTXMALI = C(1)*LNRTUSD_A + C(2)*LNRTTUFE + C(3)*LNRTTDI + C(4)*LNRTM2 } \\
& + \text { C(5)*LNRTKFE + C(6)*LNRTCLI + C(7)*LNRTAULON + C(8)*LNRTAPIFON + C(9) }
\end{aligned}
$$

(2) numaralı denklemin çalıştırılması sonucunda çıktılar Tablo 1'de sunulmuştur.

Tablo 1. BİST Ulusal Endeks

Dependent Variable: LNRTXU100

Method: Least Squares

Sample (adjusted): 2011M02 2018M12

Included observations: 95 after adjustments

\begin{tabular}{crrrr}
\hline \hline Variable & Coefficient & Std. Error & t-Statistic & Prob. \\
\hline LNRTUSD_A & $-0,099670$ & 0,271143 & $-0,367592$ & 0,7141 \\
LNRTTUFE & 0,494744 & 0,768662 & 0,643643 & 0,5215 \\
LNRTTDI & $-0,159231$ & 0,152098 & $-1,046898$ & 0,2981 \\
LNRTM2 & $-0,632849$ & 0,450793 & $-1,403857$ & 0,1640 \\
LNRTKFE & $-0,697174$ & 1,566498 & $-0,445052$ & 0,6574 \\
LNRTCLI & 3,521575 & 3,091581 & 1,139086 & 0,2578 \\
LNRTAULON & 0,010638 & 0,184215 & 0,057747 & 0,9541 \\
LNRTAPIFON & $-0,105402$ & 0,073323 & $-1,437512$ & 0,1542 \\
C & 0,003117 & 0,023449 & 0,132927 & 0,8946 \\
\hline \hline R-squared & 0,145924 & Mean dependent var & & 0,003856 \\
Adjusted R-squared & 0,066476 & S,D, dependent var & & 0,061080 \\
S.E. of regression & 0,059015 & Akaike info criterion & & $-2,732099$
\end{tabular}


Sum squared resid

Log likelihood

F-statistic

Prob(F-statistic)
0,299520 Schwarz criterion

138,7747 Hannan-Quinn criter,

1,836708 Durbin-Watson stat

0,081043
$-2,490152$

$-2,634334$

2,282578

Prob(F-statistic) değeri 0,05'in altında olmadı̆̆ ulaşılmaktadır. Modelle çalışılması uygun değildir. (3) numaralı denklemin çalıştırılması sonucunda çıktılar Tablo 2'de sunulmuştur.

\section{Tablo 2 BİST Mali Endeks}

Dependent Variable: LNRTXMALI

Method: Least Squares

Sample (adjusted): 2011M02 2018M12

Included observations: 95 after adjustments

\begin{tabular}{|c|c|c|c|c|}
\hline Variable & Coefficient & Std. Error & $\mathrm{t}$-Statistic & Prob. \\
\hline LNRTUSD_A & $-0,112509$ & 0,305241 & $-0,368589$ & 0,7133 \\
\hline LNRTTUFE & 0,386581 & 0,865329 & 0,446745 & 0,6562 \\
\hline LNRTTDI & $-0,173085$ & 0,171226 & $-1,010861$ & 0,3149 \\
\hline LNRTM2 & $-1,049497$ & 0,507485 & $-2,068036$ & 0,0416 \\
\hline LNRTKFE & $-0,977502$ & 1,763500 & $-0,554297$ & 0,5808 \\
\hline LNRTCLI & 3,707490 & 3,480376 & 1,065256 & 0,2897 \\
\hline LNRTAULON & 0,054778 & 0,207382 & 0,264143 & 0,7923 \\
\hline LNRTAPIFON & $-0,121496$ & 0,082543 & $-1,471907$ & 0,1447 \\
\hline $\mathrm{C}$ & 0,008654 & 0,026398 & 0,327833 & 0,7438 \\
\hline R-squared & 0,198434 & Mean dependent var & & 0,000738 \\
\hline Adjusted R-squared & 0,123870 & S,D, dependent var & & 0,070978 \\
\hline S.E. of regression & 0,066437 & Akaike info criterion & & $-2,495183$ \\
\hline Sum squared resid & 0,379593 & Schwarz criterion & & $-2,253237$ \\
\hline Log likelihood & 127,5212 & Hannan-Quinn criter, & & $-2,397419$ \\
\hline F-statistic & 2,661249 & Durbin-Watson stat & & 2,360734 \\
\hline Prob(F-statistic) & 0,011671 & & & \\
\hline
\end{tabular}

Prob(F-statistic) değeri 0,05 'in altında olduğu için kurulan modelin istatistiki olarak anlamlı olduğu sonucuna ulaşılmaktadır. Hata terimlerinin tanımlayıcı istatistikleri Şekil 1'de verilmiştir.

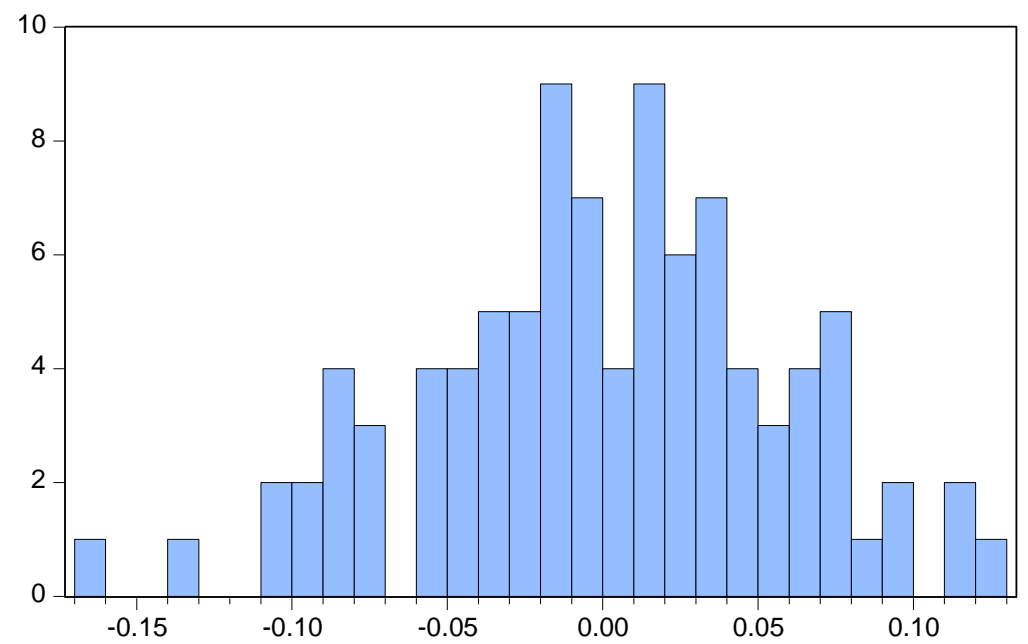

\begin{tabular}{|c|c|}
\hline \multicolumn{2}{|c|}{$\begin{array}{l}\text { Series: Residuals } \\
\text { Sample 2011M02 2018M12 } \\
\text { Observations } 95\end{array}$} \\
\hline Mean & $3.51 e-18$ \\
\hline Median & 0.000234 \\
\hline Maximum & 0.120357 \\
\hline Minimum & -0.164886 \\
\hline Std. Dev. & 0.056448 \\
\hline Skewness & -0.259190 \\
\hline Kurtosis & 2.996565 \\
\hline Jarque-Bera & 1.063724 \\
\hline Probability & 0.587510 \\
\hline
\end{tabular}

\section{Şekil 1. Hata terimlerinin tanımlayıcı istatistikleri}

Hata terimlerinin ortalamasının sıfır olduğu ve normal dağılım sergilediği gözlenmektedir. Otokorelasyon sorunun varlığı sınanmış ve sonuçlar Şekil 2'de verilmiştir. 
Sample: 2011M02 2018M12

Included observations: 95

\begin{tabular}{|c|c|c|c|c|c|c|c|c|}
\hline \multicolumn{2}{|c|}{ Autocorrelation } & \multicolumn{3}{|c|}{ Partial Correlation } & $\mathrm{AC}$ & $\mathrm{PAC}$ & Q-Stat & Prob \\
\hline 맘 & 1 & 맘 & 1 & 1 & -0.182 & -0.182 & 3.2648 & 0.071 \\
\hline 1 & I & 1 & 1 & 2 & 0.016 & -0.018 & 3.2888 & 0.193 \\
\hline I & 1 & 단 & 1 & 3 & -0.111 & -0.115 & 4.5130 & 0.211 \\
\hline 10 & 1 & 10 & I & 4 & -0.038 & -0.083 & 4.6568 & 0.324 \\
\hline 1 & 1 & 1 & 1 & 5 & 0.025 & -0.000 & 4.7199 & 0.451 \\
\hline I & יاן & 1 & اط & 6 & 0.152 & 0.150 & 7.1116 & 0.311 \\
\hline 1 & 1 & 1 & 1 & 7 & -0.013 & 0.034 & 7.1300 & 0.415 \\
\hline 담 & 1 & 담 & 1 & 8 & -0.140 & -0.142 & 9.2150 & 0.324 \\
\hline 1 & 口ا & 1 & 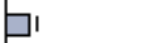 & 9 & 0.166 & 0.163 & 12.169 & 0.204 \\
\hline $1 \square$ & 1 & 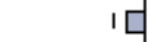 & 1 & 10 & -0.186 & -0.124 & 15.934 & 0.102 \\
\hline 1 & 1 & 1 & 1 & 11 & 0.015 & -0.086 & 15.959 & 0.143 \\
\hline 무 & 1 & $\square$ & 1 & 12 & -0.189 & -0.233 & 19.909 & 0.069 \\
\hline 1 & 1 & 10 & 1 & 13 & -0.001 & -0.097 & 19.909 & 0.097 \\
\hline 1 & 1 & 1 & 1 & 14 & -0.010 & -0.034 & 19.921 & 0.133 \\
\hline 1 & ا & 1 & 1 & 15 & 0.097 & -0.001 & 21.012 & 0.136 \\
\hline 1 & 1 & 1 & 1 & 16 & -0.011 & 0.019 & 21.025 & 0.178 \\
\hline$\sqsubset$ & 1 & 1口 & 1 & 17 & -0.214 & -0.186 & 26.432 & 0.067 \\
\hline 1 & 1 & 담 & 1 & 18 & -0.056 & -0.140 & 26.806 & 0.083 \\
\hline 1 & 1 & 1 & 1 & 19 & -0.002 & -0.004 & 26.807 & 0.109 \\
\hline 1 & יا口 & 1 & 1 & 20 & 0.133 & 0.025 & 28.990 & 0.088 \\
\hline 1 & b & 1 & P & 21 & 0.087 & 0.102 & 29.925 & 0.093 \\
\hline 1 & 1 & 1 & 1 & 22 & -0.014 & -0.045 & 29.952 & 0.120 \\
\hline 1 & 1 & 1 & 1 & 23 & -0.020 & 0.054 & 30.001 & 0.149 \\
\hline 1 & b & 1 & p & 24 & 0.068 & 0.081 & 30.598 & 0.166 \\
\hline 1 & 1 & 1 & 1 & 25 & 0.061 & 0.048 & 31.084 & 0.186 \\
\hline I & 1 & 1 & 1 & 26 & -0.047 & -0.036 & 31.381 & 0.214 \\
\hline 1 & 1 & 1 & 1 & 27 & 0.021 & -0.044 & 31.440 & 0.253 \\
\hline 1 & 1 & 1 & 1 & 28 & -0.010 & -0.015 & 31.454 & 0.297 \\
\hline 1 & 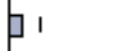 & 1 & 1 & 29 & 0.089 & -0.005 & 32.559 & 0.296 \\
\hline 1 & ים & 1 & 2 & 30 & 0.125 & 0.083 & 34.773 & 0.251 \\
\hline 1 & 1 & 1 & 1 & 31 & -0.097 & -0.041 & 36.126 & 0.241 \\
\hline 10 & 1 & 1 & 1 & 32 & -0.051 & 0.004 & 36.500 & 0.267 \\
\hline 1 & 1 & 1 & 1 & 33 & -0.056 & 0.015 & 36.973 & 0.290 \\
\hline 1 & 1 & 1 & 1 & 34 & 0.014 & -0.039 & 37.002 & 0.332 \\
\hline 1 & 1 & 1 & 1 & 35 & 0.041 & 0.010 & 37.260 & 0.365 \\
\hline 10 & 41 & 1 다 & 1 & 36 & -0.052 & -0.108 & 37.679 & 0.392 \\
\hline
\end{tabular}

\section{Şekil 2. Otokorelasyon Test Sonuçları}

Tüm değerler sınır çizgileri aralığında kaldığı için otokorelasyon sorunu yoktur sonucuna ulaşılır. Modelin açıklama gücü düşük ve M2 haricinde diğer tüm değişkenler istatistiki olarak anlamsız görülmektedir. Çoklu bağıntı sorunu varlığını kontrol etmekte fayda bulunmaktadır.

\section{Tablo 3 Çoklu Bağıntı Testi}

Variance Inflation Factors

Sample: 2011M01 2018M12

Included observations: 95

\begin{tabular}{cccc}
\hline \hline Variable & $\begin{array}{c}\text { Coefficient } \\
\text { Variance }\end{array}$ & $\begin{array}{c}\text { Uncentered } \\
\text { VIF }\end{array}$ & $\begin{array}{c}\text { Centered } \\
\text { VIF }\end{array}$ \\
\hline \hline LNRTAPIFON & 0.005376 & 1.218186 & 1.188661 \\
LNRTAULON & 0.033935 & 1.079707 & 1.079158 \\
LNRTKFE & 2.453918 & 8.043453 & 1.123754 \\
LNRTM2 & 0.203215 & 2.925339 & 2.040596 \\
LNRTTUFE & 0.590841 & 2.684249 & 1.628920
\end{tabular}




LNRTUSD_A
LNRTTDI
LNRTCLI
C

0.073518

0.023134

9.557873

0.000550
2.968577

1.155748

5.873788

14.99841
2.633423

1.154133

1.227844

NA

Tablo 3'teki sonuçlar çoklu bağıntının sorun olmadığını işaret etmektedir. Değişen varyans olup olmadığı White testi ile sınanmış sonuçlar Tablo 4’te verilmiştir.

Tablo 4 Değişen Varyans Testi

Heteroskedasticity Test: White

\begin{tabular}{lllr}
\hline \hline F-statistic & 2.484445 & Prob. F(8,86) & 0.0179 \\
Obs*R-squared & 17.83394 & Prob. Chi-Square(8) & 0.0225 \\
Scaled explained SS & 14.27423 & Prob. Chi-Square(8) & 0.0749 \\
\hline \hline
\end{tabular}

Test Equation:

Dependent Variable: RESID^2

Method: Least Squares

Sample: 2011M02 2018M12

Included observations: 95

\begin{tabular}{|c|c|c|c|c|}
\hline Variable & Coefficient & Std. Error & t-Statistic & Prob. \\
\hline $\mathrm{C}$ & 0.002258 & 0.001693 & 1.333655 & 0.1858 \\
\hline LNRTUSD_A^2 & 0.136957 & 0.407068 & 0.336446 & 0.7374 \\
\hline LNRTTUFE^2 & 3.409984 & 1.780720 & 1.914947 & 0.0588 \\
\hline LNRTTDI^2 & -0.214277 & 0.253995 & -0.843626 & 0.4012 \\
\hline LNRTM2^2 & -0.291255 & 1.079787 & -0.269733 & 0.7880 \\
\hline LNRTKFE^ $^{\wedge} 2$ & -1.782974 & 6.742387 & -0.264443 & 0.7921 \\
\hline LNRTCLI^2 & 34.07964 & 46.25691 & 0.736747 & 0.4633 \\
\hline LNRTAULON^2 & 0.908787 & 0.294433 & 3.086561 & 0.0027 \\
\hline LNRTAPIFON^2 $^{\wedge}$ & -0.012092 & 0.028998 & -0.416988 & 0.6777 \\
\hline R-squared & 0.187726 & Mean dependent var & & 0.003996 \\
\hline Adjusted R-squared & 0.112165 & S.D. dependent var & & 0.005614 \\
\hline S.E. of regression & 0.005290 & Akaike info criterion & & -7.556075 \\
\hline Sum squared resid & 0.002407 & Schwarz criterion & & -7.314129 \\
\hline Log likelihood & 367.9136 & Hannan-Quinn criter. & & -7.458310 \\
\hline F-statistic & 2.484445 & Durbin-Watson stat & & 2.236625 \\
\hline $\operatorname{Prob}($ F-statistic) & 0.017851 & & & \\
\hline
\end{tabular}

Heteroskedastisite ile ilgili birbiriyle çelişen sonuçlar ortaya çıkmıştır.

\section{Tartışma ve Sonuç}

BİST 100 ve BİST Mali endekslerinin bağımlı değişken olarak tanımlandığı ve finansal bağlantılılık kavramından hareketle risk yönetim sistemlerinin kurulmasında, kullanılması uygun olabilecek faktörlerin tespit edilmesinin amaçlandığ 1 çalışmada, endeksler üzerinde etkili olacağ edilmiştir.

Tanımlanmış birinci regresyon modeli, denklem (2)'de ifade edilen BİST 100 endeksi için kurulan model, istatistiki olarak anlamlı sonuç vermemiştir. Anlamsız istatistiki model tespit edildiğinde analize devam edilmesi uygun değildir. Modelin yeniden formüle edilerek BIST 100'deki getirilerin değişimini tahmin edebilecek bir modelin kurulması uygundur.

Denklem (3)'de ifade edilen, BİST Mali için kurulan modelin istatistiki olarak anlamlı olduğu tespit edilmiş ancak M2 para arzı dışındaki değişkenlerin istatistiki olarak anlamlı olmadığı bulgularıyla karşılaşılmıştır. Çoklu doğrusal regresyon modelinin varsayımları incelenerek sorunun kaynağı araştırılmıştır. Modelin hata terimlerinin 
ortalamasının sıfır olduğu ve normal dağılım sergilediği tespit edilmiştir. Otokorelasyon olup olmadı̆̆ araştırılmış; ancak otokorelasyonun varlığı tespit edilememiştir. Çoklu bağıntı problemi olabileceğinden sınama yapılmıştır; ancak çoklu bağıntı problemiyle de karşılaşılmamıştır. White testi sınamasıla heteroskedastisite incelenmiştir. Test istatistiklerinin birbiriyle çelişen sonuçlar vermekte olduğu belirlenmiştir. Değişen varyans problemi olduğunu iki test söylerken, bir test değişen varyans olmadığını belirtmektedir. Değişen varyans var ise ve bu durum çalışmada ihmal edilirse en küçük kareler yöntemiyle çalışıldığında standart hatalar yanlış olabilir ve yapılacak çıkarımlar yanıltıcı sonuçlar verebilir. Böyle bir durumda yansız tahmin ediciler sınıfı minimum varyansa sahip olamayacak ancak en küçük kareler tahmin edicileri hala tarafsız ve aynı zamanda tutarlı bir katsayı verecektir. Risk gözetim mekanizması tesis edilmeye çalışırken karşı karşıya kalınabilecek bu tarz bir ihtimal konunun amacına zarar verebilecektir, bu nedenle heteroskedastisite sorununu ortadan kaldırmanın yolları aranmalıdır. Uygulamaya alınabilecek alternatif çözüm olarak genelleştirilmiş veya ağırlıklandırılmış en küçük kareler yöntemiyle çalışmak değerlendirilebilir; ancak bu metodoloji heteroskedastisitenin kaynağının bilinmesi gerektirmektedir. Modele dahil edilen değişkenlerin değiştirilmesi bir diğer çözüm olarak sunulabilir. Özetle, kullanılan değişkenlerle oluşturulan çoklu doğrusal regresyon modeliyle gerek BİST 100'ü gerekse BİST Mali endeksini etkileyen faktörler, dolar alış kuru, tüketici fiyat endeksi, tarım dişı işsizlik, M2 para arzı, konut fiyat endeksi, sanayi üretim endeksi, altın fiyatları ve TCMB ağırlıklı ortalama fonlama maliyetidir denilememektedir.

\section{Kaynakça}

Alper, D., \& Kara, E. (2017). Borsa İstanbul'da Hisse Senedi Getirilerini Etkileyen Makroekonomik Faktörler: BIST Sınai Endeksi Üzerine Bir Araştırma. Süleyman Demirel Üniversitesi İktisadi ve İdari Bilimler Fakültesi Dergisi, 22(3), 713-730. Erişildi http://iibfdergi.sdu.edu.tr/assets/uploads/sites/352/files/yil-2017cilt-22-sayi-3-yazi06-17082017.pdf

BenMim, I., \& BenSaïda, A. (2019). Financial contagion across major stock markets: A study during crisis episodes. The North American Journal of Economics and Finance, 48, 187-201. https://doi.org/10.1016/J.NAJEF.2019.02.005

Brooks, C. (2008). Introductory Econometrics for Finance (Second Edi). Cambridge University Press.

Camilleri, S. J., Scicluna, N., \& Bai, Y. (2019). Do stock markets lead or lag macroeconomic variables? Evidence from select European countries. North American Journal of Economics and Finance, 48(August 2018), 170186. https://doi.org/10.1016/j.najef.2019.01.019

Çankaya, S. (2013). Konut Fiyatları ve Makroekonomik Faktörler Arası İlişkiye Global Bakış. Maliye ve Finans Yazılarl, 27(100), 143-154. Erişildi http://dergipark.gov.tr/mfy/issue/16280/170761

Ceylan, N. B. (2005). G-7 Ülkelerinin Borsalarının İstanbul Menkul Kıymetler Borsası Üzerindeki Etkileri. IMKKB Dergisi, 8(32), 37-56. Erişildi https://www.borsaistanbul.com/kurumsal/yayinlar/borsa-istanbulreview/makaleler-sayi-32

Chen, Y., Eaton, G. W., \& Paye, B. S. (2018). Micro(structure) before macro? The predictive power of aggregate illiquidity for stock returns and economic activity. Journal of Financial Economics, 130(1), 48-73. https://doi.org/10.1016/J.JFINECO.2018.05.011

Coşkun, M., Kiracı, K., \& Muhammed, U. (2016). Seçilmiş Makroekonomik Değiş̧kenlerle Hisse Senedi Fiyatları Arasındaki İlişki: Türkiye Üzerine Ampirik Bir İnceleme. Finans Politik \& Ekonomik Yorumlar, 53(616), 61-64. Erişildi http://www.ekonomikyorumlar.com.tr/files/articles/152820006115_5.pdf

Durukan, M. B. (1999). İstanbul Menkul Kıymetler Borsasında Makroekonomik Değişkenlerin Hisse Senedi

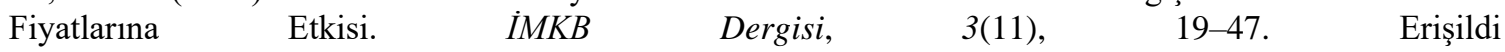
https://www.borsaistanbul.com/datum/imkbdergi/IMKB_Dergisi_Turkce11.pdf

Gençtürk, M. (2009). Finansal Kriz Dönemlerinde Makroekonomik Faktörlerin Hisse Senedi Fiyatlarına Etkisi. Süleyman Demirel Üniversitesi İktisadi ve İdari Bilimler Fakültesi Dergisi, 14(1), 127-136. Erişilldi http://dergipark.gov.tr/sduiibfd/issue/20831/223140

Kao, Y.-S., Chuang, H.-L., \& Ku, Y.-C. (2019). The empirical linkages among market returns, return volatility, and trading volume: Evidence from the S\&P 500 VIX Futures. The North American Journal of Economics and Finance. https://doi.org/10.1016/J.NAJEF.2018.10.019

Karacaer, S., \& Topuz, Y. V. (2009). ABD Doları Değerindeki Değişmenin Gelişmekte Olan Ülkelerin Hisse Senedi Endekslerine Etkisi:Ocak 2001-Kasım 2006 Örneği. IMKB Dergisi, 11(42), 1-18. Erişilldi https://www.borsaistanbul.com/datum/imkbdergi/IMKB_Dergisi_Turkce42.pdf

Kaya, A., \& Öndeş, T. (2013). Türkiye'de Yabancı Portföy Yatırımlarının Belirleyicileri. IMKB Dergisi, 13(52), 19-39. Erişildi https://www.borsaistanbul.com/datum/imkbdergi/IMKB_Dergisi_Turkce52.pdf 
Kırbaş Kasman, S. (2005). Hisse Senedi Getirilerinin Oynaklığı ile Makroekonomik Değişkenlerin Oynaklı̆̆ Arasındaki İlişki Türkiye'de Ödeyememe Riski: Ekonometrik Yaklaşım. IMKB Dergisi, 8(32), 1-10. Erişildi https://www.borsaistanbul.com/datum/imkbdergi/IMKB_Dergisi_Turkce32.pdf

Koçyiğit, M., \& Kılıç, A. (2008). Leasing Sektöründe KDV Oranı Değişikliğinin İMKB'de İşlem Gören Leasing Şirketlerinin Hisse Senedi Getirisine Etkisi. Muhasebe ve Finansman Dergisi, (40), 165-174. Erişildi http://dergipark.gov.tr/mufad/issue/35615/395773

Omağ, A. (2009). Türkiye'de 1991-2006 Döneminde Makro Ekonomik Değişkenlerin Hisse Senedi Fiyatlarına Etkisi. Öneri, 32(8), 283-288. Erişildi http://dosya.marmara.edu.tr/sbe/Öneri dergisi arşivi 2/2009_neri_Say_32.pdf

Özer, A., Kaya, A., \& Özer, N. (2011). Hisse Senedi Fiyatları ile Makroekonomik Değişkenlerin Etkileşimi. Dokuz Eylül Üniversitesi İktisadi İdari Bilimler Fakültesi Dergisi, 26(1), 163-182. Erişildi http://deu.dergipark.gov.tr/deuiibfd/issue/22731/242593

Sakarya, Ş., \& Sezgin, H. (2015). Sendikasyon Kredisi Kullanımının Bankaların Hisse Senedi Getirilerine Etkisi: Olay Çalışması Yöntemiyle BİST'de Bir Uygulama. Bankacılar Dergisi, 26(92), 5-24. Erişildi www.tbb.org.tr

Sayılgan, G., \& Süslü, C. (2011). Makroekonomik Faktörlerin Hisse Senedi Getirilerine Etkisi: Türkiye ve Gelişmekte Olan Piyasalar Üzerine Bir İnceleme. BDDK Bankacılık ve Finansal Piyasalar Dergisi, 5(1), 73-97.

Singhal, S., Choudhary, S., \& Biswal, P. C. (2019). Return and volatility linkages among International crude oil price, gold price, exchange rate and stock markets: Evidence from Mexico. Resources Policy, 60, $255-261$. https://doi.org/10.1016/J.RESOURPOL.2019.01.004

Topaloğlu, E. E., \& Karakozak, Ö. (2018). Makroekonomik Faktörler ve Pay Senedi Getirisi: BIST Banka Endeksi Firmaları Üzerine Panel Veri Analizi. Muhasebe ve Finansman Dergisi, (78), 199-216. https://doi.org/10.25095/mufad.412693

Uçan, O., Güzel, F., \& Acar, M. (2017). Makroekonomik Göstergelerin Borsa Endeksi Üzerine Etkisi: Panel Veri Analizi İle Borsa İstanbul'da Bir Uygulama. Muhasebe Bilim Dünyası Dergisi, 19(2), 509-523. Erişildi $\mathrm{http} / / /$ search.ebscohost.com/login.aspx?direct=true\&db=a9h\&AN=124102885\&lang=tr\&site=eds-live

Varlık, S. (2017). Ülke Risk Primi Şokunun Bankacılık Sisteminin Sağlamlığına Etkisi: SVAR Modeli Çerçevesinde Türkiye Örneği. $\quad$ Sosyoekonomi, $25(33), \quad 103-126$. https://doi.org/10.17233/sosyoekonomi.286476

Yüksel, S., \& Özsarı, M. (2017). Türkiye Cumhuriyet Merkez Bankası'nın Döviz Rezervlerine Etki Eden Makroekonomik Faktörlerin Belirlenmesi. Finans Politik \& Ekonomik Yorumlar, 54(631), 41-53. Erişildi http://www.ekonomikyorumlar.com.tr/files/articles/1528455771.pdf

\section{Extended Abstract}

The network of relationships between the actors involved in the financial ecosystem influences a wide range of people thanks to the links brought by globalization. The limits of the effects are shaped by the strength of the financial ties of the elements in the financial system. There are many variables that can be examined within the scope of financial interconnectedness. These variables can be established for a single country sample or for multiple country samples. Such studies are mentioned in the literature section of the study. In this study, the effects of macroeconomic factors on stock prices are taken into consideration. In the study, which aims to determine the factors that may be suitable for the establishment of relatively proactive risk management systems within the scope of financial connectivity, the explanoratory power of the Borsa Istanbul financial sector index returns and the Borsa Istanbul national index returns was investigated. The CBRT's electronic data distribution system (EDDS) was used to determine monthly factors that affect Borsa Istanbul Stock Price and BIST 100 index by considering literature studies and interaction with financial sector. Based on the literature, it was decided to use multiple linear regression model as the research model. In its broadest definition, regression is an attempt to explain movements in one variable with one or more variables (Brooks, 2008). Independent variables are expressed by $\mathrm{x}$ and dependent variable by $y$. The generalized expression of the multiple linear regression model is shown in equation (1). Multiple linear regression models were established from the selected CBRT EDDS monthly data for the period 2011: 01 2018: 12 . The data are 1 Ounce of Gold London Sales Price (USD / Ounce) - Level, (PRICE) BIST 100 Index, According to Closing Prices (January $1986=1$ ) - Level, (PRICE) According to BIST Financial Index Closing Prices (31-12-1990 = 33) - Level, CBRT Weighted Average Funding Cost - Level, (USD) US Dollar (Foreign Exchange Buying) - Level, (USD) US Dollar (Foreign Exchange Sales) - Level, M2 (Thousand TL) - Level, Consumer Price Index (General) ) -Surface, Housing Price Index (PPI) -Surface, General Budget Balance-Level, 
MBONCU-CPS (Including Trend) -Surface, Non-agricultural unemployment rate (\%) - Level. It was found that the model established for Borsa Istanbul national index was not statistically significant, although the model established for Borsa Istanbul financial sector index was statistically significant, the explanatory power of the model was low and all other variables except M2 were considered statistically insignificant. It was concluded that it would be more appropriate to work with different models in order to determine the factors that may be appropriate when trying to establish a risk surveillance mechanism by identifying the findings regarding the possibility of changing variance problem. As an alternative solution, generalized or weighted least squares method can be considered; however, this methodology requires knowledge of the source of heterocastasticity. Modifying the variables included in the model can be presented as another solution. In summary, it would be inconveninent to present the factors affecting both BIST 100 and BIST Financial Index by using multiple linear regression model with variables used as, dollar buying rate, consumer price index, non-agricultural unemployment, M2 money supply, housing price index, industrial production index, gold prices and CBRT weighted the average funding cost. 